\title{
A RARE CASE REPORT OF DIROFILARIA IN SUBCONJUNCTIVAL SPACE
}

Manjula Y. $\mathrm{M}^{1}$, Suma $\mathrm{C}^{2}$

\section{HOW TO CITE THIS ARTICLE:}

Manjula Y. M, Suma C. "A Rare Case Report of Dirofilaria in Subconjunctival Space". Journal of Evolution of Medical and Dental Sciences 2014; Vol. 3, Issue 62, November 17; Page: 13784-13786,

DOI: $10.14260 /$ jemds/2014/3843

ABSTRACT: Dirofilariasis is a zoonotic infection. In India dirofilarial cases are rare; few cases are reported from Kerala and Karnataka. We report a rare case of live dirofilarial worm removed from left eye sub conjunctival space of a 27 years old male.

KEYWORDS: Dirofilaria, sub conjunctival space.

INTRODUCTION: Dirofilaria is a zoonotic infection seen worldwide. They are natural parasites of dogs, cats and fox. There are around 40 different species. Human dirofilariasis is an accidental infection by species such as Dirofilariarepens, Dirofilariaimmitis, Dirofilariatenuis.Dirofilaria in human are rarely reported. We report here a rare case of dirofilaria in subconjucntival space.

CASE REPORT: A 27 year old male patient, from Bangalore, Karnataka came to ophthalmology OPD at BGS GIMS Hospital with complaint of swelling in left lower eyelid since 15 days, associated with pain and pricking sensation and redness since 4 days. Slit lamp examination revealed left lower lid subconjunctival swelling resembling a chalazion measuring $10 \mathrm{mmX} 15 \mathrm{~mm}$ with a pointing tip associated with conjunctival congestion.

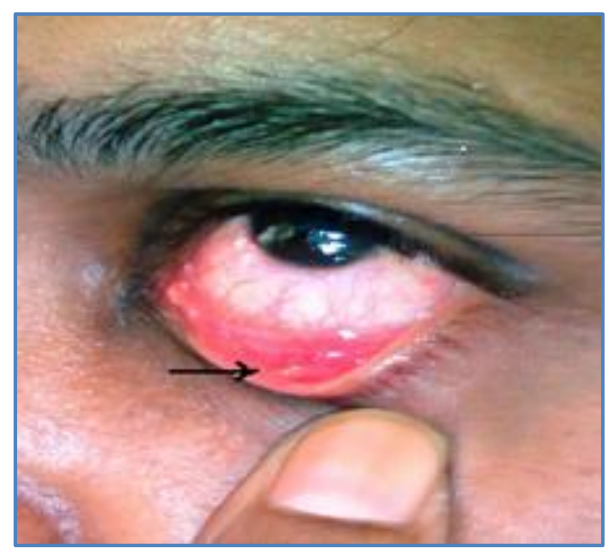

Fig. 1: Nodular swelling in subconjunctival space

Under topical paracaine anaesthesia with a cotton bud we tried to manipulate the swelling but it was not of much information.

Other ocular examination was normal in both eyes visual acuity in both eye was $6 / 6$ and N6.

The patient was taken to OT and under $4 \%$ xylocaine local anaesthesia a small incision was made in the palpebral conjunctiva of left lower lid just at the pointing tip of the swelling. White thread like worm was noticed which was pulled with the help of non-toothed forceps. The worm was alive and motile. 
Gross examination of worm showed a thin cylindrical transparent live worm measuring $4.5 \mathrm{~cm}$ long. The worm was sent to microbiological examination.

Systemic examination of the patient did not show any evidence of subcutaneous swelling or any skin rashes in the body.

Investigations showed raised absolute eosinophil count (403cells $/ \mathrm{mcl}$ ).

Urine and stool examinations were normal.

Patient was put on topical moxifloxacin $0.3 \%$ antibiotic eye drops and prednisolone acetate $1 \%$ eye drops and systemic deworming was done by diethylcarbamazine.

Microbiological report suggested that the specimen was dirofilariarepens confirmed by presence of thick laminated cuticle with longitudinal cuticular ridges.
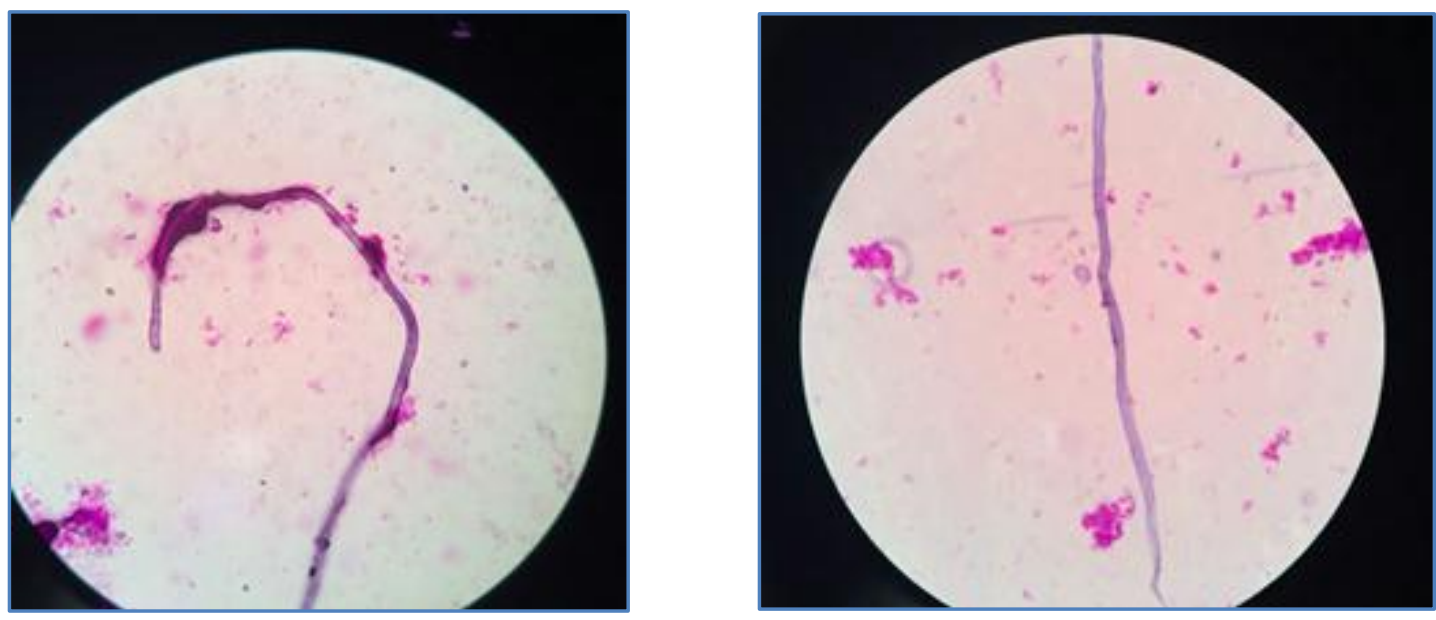

Fig. 2 and Fig. 3: Microscopic picture of

worm isolated from subconjunctival space

DISCUSSION: Dirofilariasis is zoonotic disease reported worldwide mainly from European continent ${ }^{1}$. In India sub conjunctival dirofilaria is a rare entity. ${ }^{2}$ Few cases are reported in Kerala and Karnataka states.3,4 They are natural parasites of dogs, cats and fox. The vectors for this parasite are mosquitoes Culex and Anopheles. The adult female worms of Dirofilaria release microfilariae into the circulation of the infected animals, which are ingested by the vectors during a blood meal. The infection is transmitted to humans by insect vector like mosquito. ${ }^{4}$

The Ocular dirofilariasis caused by dirofilariarepens presents with subcutaneous and subconjunctival eyelid swelling. It also affects periorbital region. Sub conjunctival space infection is rare. ${ }^{5}$ Dirofilaria female worm measures about 8 to $13 \mathrm{~cm}$ and male worm measures about 4 to $5 \mathrm{~cm}$. The diagnostic confirmation is by studying the morphology of worm which shows thick laminated cuticle. Dirofilariarepens shows additional presence of external longitudinal cuticular ridges with absence of microfilaremia.Dirofilariaimmitis differentiated from dirofilariarepens with absence of external longitudinal cuticular ridges and associated with microfilaremia.

The treatment in case of dirofilariaocularis is surgical removal of the worm. In our case symptoms resolved quickly following surgical removal of worm and topical antibiotic steroid drops along with systemic deworming by DEC which was followed up for 3 weeks. 
An accurate diagnosis can be made by a PCR-based DNA analysis which was not done in our case. ${ }^{6}$ In our country no standard antibody detecting tests are available for the dirofilariarepens infection which can be used as additional confirmatory test like Ruiz Moreno et al have demonstrated in 1998.

CONCLUSION: Human ocular dirofilariasis are rare because many cases are undiagnosed or not reported. Increase awareness about ocular dirofilariasis may improve prevalence rate of ocular dirofilariasis and patient care.

\section{REFERENCES:}

1. Ruiz-Moreno JM, Bornay-Llinares FJ, Maza GP, Medrano M, Simon F, Eberhard ML. Subconjunctival Infection with Dirofilariarepens: Serological Confirmation of Cure Following Surgery. Arch Ophthalmol 1998; 116:1370-2.

2. Khurana S, Singh G, Bhatti HS, Malla N. Human subcutaneous dirofilariasis in India: A report of three cases with brief review of literature. Indian J Med Microbiol. 2010;28:394-96.

3. Human dirofilariasis: an emerging zoonosis in indiaReshma G Kini.J.B, Leelaprathvi, Shetty Raphael et al. Journal of parasitic Diseases 2013.

4. Sathyan P, Manikandan P, Bhaskar M, Padma S, Singh G, Appalaraju B. Subtenons infection by Dirofilariarepens. Indian J Med. Microbiol.2006;24:61-62.

5. Sekhar HS, Srinivasa H, Batru R, Mathai E, Shariff S, Macaden RS. Human ocular Dirofilariasis in Kerala South India. Indian J PatholMicorbiol 2000; 43:77-9.

6. An interesting case of a subcutaneous nodule:Achappa, B. and Madi, D. and Mahalingam, S. Journal of Clinical and Diagnostic Research. 2013; 7(2): 364-365.

\section{AUTHORS:}

1. Manjula Y. M.

2. Suma C.

\section{PARTICULARS OF CONTRIBUTORS:}

1. Assistant Professor, Department of Ophthalmology, BGS Global Institute of Medical Science, Bangalore.

2. Senior Resident, Department of Ophthalmology, BGS Global Institute of Medical Science, Bangalore.

\author{
NAME ADDRESS EMAIL ID OF THE \\ CORRESPONDING AUTHOR: \\ Dr. Manjula Y. M, \\ M Block, Apt No. 701, \\ Brigade Gateways, \\ Rajkumar Road, Malleswaram, \\ Bangalore-560055. \\ Email: drmanjumahesh50@gmail.com \\ drsumi13@gmail.com
}

Date of Submission: 27/09/2014.

Date of Peer Review: 28/09/2014.

Date of Acceptance: 12/11/2014.

Date of Publishing: 17/11/2014. 